\title{
NUMERICAL INVESTIGATIONS ON FLOW CHARACTERISTICS OF SAND- WATER SLURRY THROUGH HORIZONTAL PIPELINE USING COMPUTATIONAL FLUID DYNAMICS
}

\author{
Shofique Uddin Ahmed ${ }^{1, *}$, Rajesh Arora $^{1}$, Om Parkash $^{1}$
}

\begin{abstract}
The study presents the numerical computational fluid dynamics (CFD) analysis of sand-water slurry flow with different sand particle sizes viz. $90 \mu \mathrm{m}, 125 \mu \mathrm{m}, 150 \mu \mathrm{m}, 200 \mu \mathrm{m}$ and $270 \mu \mathrm{m}$ having specific gravity of 2.65 through a $103 \mathrm{~mm}$ diameter, $5.5 \mathrm{~m}$ long horizontal pipeline for a high flow velocity of $5.4 \mathrm{~m} / \mathrm{s}$ at various solid volumetric concentrations viz. $10 \%, 20 \%, 30 \%, 36 \%$ and $40 \%$. Granular version of Eulerian two-phase model with dispersed particles along with RNG -epsilon approach has been utilized. Non-uniform structured mesh with a refinement near the wall boundary has been selected for discretizing the computational flow domain while NavierStokes governing equations are solved in FLUENT 14.0. The effects of the size of sand particles and solid volumetric concentrations on territorial concentration distributions, particle flow velocity and pressure drops have been studied and analyzed. Generalized mathematical correlation has been developed from the simulated results for calculating the consequences of the size of solid particles and solid volumetric concentration on pressure drop analytically. The simulated outcomes of pressure drop are validated with the experimental results. These outcomes will be very helpful in the setup of an experimental model for sand/water slurry flow pipelines in many industries viz. mining, construction, power generation etc.
\end{abstract}

\section{Keywords: CFD Modeling, Eulerian Two-Phase Model, RNG K-Epsilon Model, Concentration Distribution, Flow Velocity Distribution, Pressure Drop, Slurry Pipeline}

\section{INTRODUCTION}

Conveyance of solid materials through pipelines over a long distance is a well-known mode of transportation over the years. This mode offers several advantages over conventional modes as reduction of air pollution, noise pollution, road traffic etc. Therefore, it is essential to have detailed knowledge about various flow parameters such as flow velocity, solid particle concentration, pressure drop etc. in a slurry flow for effective solid material transportation through pipelines. Comprehensive studies of these flow parameters allow establishing an accurate prediction of slurry flow and adaptation of optimal pipe design. It is studied that the solid particle concentration distribution is one of the major influencing parameters for accurate prediction of flow arrangements in slurry flow.

Computational fluid dynamics (CFD) is a sophisticated platform that provides the numerical modeling of various complex multiphase flow problems with a greater ease and low costs which is almost impossible with experimental method. It provides exclusive propaganda for the local variation of different flow variables interior to the fluid domain. Researches began from the third decades of $20^{\text {th }}$ century for establishing a general solution for the accurate prediction of different slurry flow variables like solid concentration distribution, distribution of flow velocity and pressure drop. Initial studies in this area includes the work of O'brien [1] and Rouse [2] who studied the concentration distribution of very low volumetric concentration solid particles in an open channel gravitybased flow using a diffusion model. Some of the prominent outcomes in these fields are given by Shook and Daniel [3] who predicted the buoyancy of solid particles in a stationary bed slurry flow regime. They derived a theoretical equation necessary for hydraulic gradient for the smooth transportation of slurry flow through pipelines. Wasp et. al [4] performed an experimental investigation to predict the spatial distribution of solid particles in slurry pipelines. Turian and Yuan [5] developed a correlation for satisfactory prediction of pressure drop from their experimental work on slurry flow through pipelines considering homogenous, heterogeneous, stationary bed and saltation slurry flow regime. Seshadri [6] proposed an improved model for forecasting the solid concentration distribution for the flow of solid materials in circular pipes, rectangular ducts and open channel flow. Roco and Shook [7] proposed an explicit algorithm based differential equation for numerical analysis of slurry flow through

\footnotetext{
This paper was recommended for publication in revised form by Regional Editor Sandip Kale.

${ }^{1}$ Department of Mechanical Engineering, Amity University Haryana, India

*E-mail address: uddinshofique1991@gmail.com

Orcid id: 0000-0002-9064-3768; 0000-0001-9234-4115; 0000-0001-7080-570X

Manuscript Received 23 May 2018, Accepted 29 August 2018
} 
pipelines having various pipe diameters and solid concentration below 40\%. Further, they [8] proposed a computational technique for coal-water heterogeneous slurry flow pipelines considering two-phase analysis for the prediction of particle size, velocity and concentration distributions. Doron et. al [9] conducted an empirical investigation of coarse particles slurry flow through horizontal pipelines. They also proposed a physical model which was dependent on two-layer model for analysis of pressure drop and flow patterns. Gillies et. al [10] established a two-layer model to figure out the pressure gradient in a coarse particle of sand, gravel and coal slurry flow through horizontal pipes. Later, Gillies and Shook [11] performed an empirical analysis for predicting the influence of distributions of solid particle concentration in solid-fluid slurry flow in horizontal pipeline. The interaction of particles was found to be restricted near-wall region of the pipe, interaction being more for larger particles in smaller pipes. An experimental study of slurry flow consisting of solid particles and viscous Newtonian fluid was performed by Gillies et. al [12]. The experimental results showed that pressure gradient of $2 \mathrm{Kpa} / \mathrm{m}$ is necessary for smooth transport of sand through the pipeline. Gillies and Shook [13] developed a two-layer approach to predict the solid concentration behaviour in highly concentrated ( $35 \%$ by volume) settling slurry flow. Kaushal and Tomita [14] predicted the distribution of particle size and solid concentrations for a multi-sized particulate slurry flow through ducts having rectangular cross sections using an analytical model proposed by Karabelas. The limitations of original models were identified and modifications were adopted accordingly for prediction of concentration behaviour. An experimental investigation of sand-water slurry flow with sand particle mean diameter of $0.09 \mathrm{~mm}$ and $0.27 \mathrm{~mm}$ was conducted by Gillies et. al [15] through $103 \mathrm{~mm}$ diameter horizontal pipeline. In their investigation various flow parameters such as velocity profile, concentration distribution, in-situ solid concentration were measured.

Kaushal et. al [16] conducted an investigation of glass beads-water slurry flow having high concentration through horizontal pipeline to determine a correlation of the impact of distribution of particle size on concentration profile aswell as pressure gradient. Monteiro and Bansal [17] conducted an investigation of the four rheological approach viz. Herschel-Buckley, power, Casson and Bingham approach to predict the slurry flow parameters behaviour in ice-water slurry. The results of their analytical models were correlated with experimental data and showed a good consistency. Lahiri and Ghanta [18] developed a generalized model using CFD adopting Eulerian two-fluid model along with Standard K-epsilon approach for predicting concentration distributions, velocity distributions and pressure drop of slurry flow containing glass beads and water. Kaushal et. al [19] performed a numerical analysis of glass beads- water fine particle slurry flow at high concentrations using CFD technique by adopting Eulerian two phase model and mixture model along with RNG K-epsilon approach. Messa and Malavasi [20] urged a new two layer approach to analyze completely suspended slurry flow in horizontal pipes. This new approach claimed for introducing contemporary wall boundary conditions considering solid phase, slurry mixture viscosity which takes into account of different solution algorithm and particle shape for reducing the low computational load. A numerical model was developed by Nabil et. al [21] adopting Eulerian two phase approach and K-epsilon turbulence approach to forecast slurry flow parameters of solid-fluid slurry in horizontal pipeline. Swamy et. al [22] developed a numerical model adopting Eulerian two-phase approach for estimating the flow regimes in a slurry flow through pipelines. Gopaliya and Kaushal [23] conducted a numerical investigation of sand-water slurry containing various sand particle size in a horizontal pipeline. Eulerian multiphase model with RNG k-epsilon approach was adopted for modelingthe slurry flow. Kumar et. al [24] performed an experimental investigation and CFD modeling for slurry flow of iron ore and water at higher concentration in a horizontal pipeline. In this study slurry flow of $12 \mu \mathrm{m}$ iron-ore through $105 \mathrm{~mm}$ horizontal pipe with solid particle concentration varying from 6.23-31\% and flow velocity varying from $1.35-5.11 \mathrm{~m} / \mathrm{s}$ was used. The result was validated using appropriate CFD modeling.Wang et. al [25] performed an numerical as well as experimental investigation on pressure drop of ice slurry flow considering the heterogeneous distribution of ice slurry through horizontal pipeline. Onokoko et. al [26] conducted an experimental and CFD investigation of slurry flow containing ice and water and the flow characteristics in a long horizontal pipe. They investigated pressure drop along the pipe, outlet and inlet densities, temperature and mass flow rates of the ice slurry from their experimental setup.

This current study represents CFD analysis of the impact of the size of solid particles and solid volumetric concentration on distribution of solid particles, flow velocity and pressure gradient for a slurry flow of sand and water in horizontal pipeline. Eulerian two-phase model along with RNG k-epsilon approach are adopted for modelling the multiphase flow of sand-water slurry in horizontal pipeline having $103 \mathrm{~mm}$ pipe diameter. Length of the pipe is taken as $5.5 \mathrm{~m}$ which is longer than 50D length required for fully developed flow. Sand particles with density of $2650 \mathrm{~kg} / \mathrm{m}^{3}$ and different mean particle diameter of the order of $90 \mu \mathrm{m}, 125 \mu \mathrm{m}, 150 \mu \mathrm{m}, 200 \mu \mathrm{m}$ and $270 \mu \mathrm{m}$ are considered for a flow velocity of $5.4 \mathrm{~m} / \mathrm{s}$; varying the volumetric concentration of solid particles from $10 \%$ to $40 \%$ (viz. $10 \%, 20 \%, 30 \%, 36 \%$ and $40 \%$ ) by volume. Sand particles are considered as mono-dispersed. 
The 3D simulated result of pressure gradient for $270 \mu \mathrm{m}$ particle size at various volumetric concentration level at high velocity $(5.4 \mathrm{~m} / \mathrm{s})$ are correlated with the experimental data available in the work of Gillies et. al [15] for the validation of this current study.

\section{MATHEMATICAL MODEL}

Selection of proper mathematical model is indispensable for all numerical analysis problems keeping in view the objectives and physics of the problem. Slurry flow problem is a multiphase (solid-liquid) flow problem. Various multiphase models such as discrete phase, mixture model, Eulerian model etc. are available in FLUENT software package for modelling the multiphase flow problem. Slurry flow contains continuous (liquid) phase and discrete (solid) phase and is not considered as a diffused dilute system. The usage of discrete phase model is not possible for modelling its flow. Eulerian model and mixture model can be used for this purpose. But based on previous literature survey, the best suited model is the Eulerian model sometimes called as two- fluid model; which satisfies the laws of conservation of momentum and mass for both solid and fluid phase individually. Moreover the granular version of Eulerian model is preferred for modeling slurry flow because unlike non-granular version, it provides the option for considering the collision and friction among solid particles which is very essential for modelling the slurry flow. The granular version of Eulerian two phase model is adopted for this current study and is described as below.

\section{Eulerian Model}

The Eulerian model cannot differentiate solid-fluid and fluid-fluid multiphase flows. In Eulerian model it is assumed that the slurry flow comprises separate fluid and solid phases, and they structure continuum, so that the volume concentration of $\operatorname{solid}\left(\alpha_{\mathrm{s}}\right)$ and fluid $\left(\alpha_{\mathrm{f}}\right)$ is equal to 1. i.e. $\alpha_{\mathrm{s}}+\alpha_{\mathrm{f}}=1$. Thismodel satisfies both law of conservation of momentum and mass for solid and liquid individually. The assumptions undertaken in the present study and the forces that act on a single fluid particle are:

- $\quad$ Static pressure gradient, $\Delta \mathrm{P}$.

- Inertial force caused by interaction of particles or solid pressure gradient $\Delta \mathrm{P}_{\mathrm{s}}$.

- Differences in velocity between the solid and fluid phase causes the drag force, $K_{s f}\left(\vec{v}_{s}-\vec{v}_{f}\right)$ where, $K_{s f}$ is the drag coefficient of inter-force, where $\vec{v}_{f}$ the velocity of fluid is phase and $\vec{v}_{s}$ is the velocity of solid phase.

- $\quad$ Forces due to viscosity, $\nabla \cdot \overline{\bar{\tau}}_{f}, \overline{\bar{\tau}}_{f}$ is being the stress tensor for fluid phase.

- $\quad \rho \vec{g}$, is the body force.

- Virtual mass force, $C_{v m} \alpha_{s} \rho_{f}\left(\vec{v}_{f} \nabla \vec{v}_{f}-\vec{v}_{s} \nabla \vec{v}_{s}\right)$ where, $C_{v m}$ is the coefficient of virtual mass force and is taken as 0.5 in this current work.

- Lift force, $C_{L} \alpha_{s} \rho_{f}\left(\vec{v}_{f}-\vec{v}_{s}\right) \times\left(\nabla \times \vec{v}_{f}\right)$, where, $C_{L}$ is the coefficient of lift, taken as 0.5 in this current work.

- The particles in the present study are assumed to be fluid in nature; therefore, the stress tensor of fluid is undertaken for computational analysis.

\section{Governing Equations}

Continuity and momentum equations are formulated as [16]

Continuity equation:

$$
\nabla \cdot\left(\alpha_{t} \rho_{t} \vec{v}_{t}\right)=0, \quad t \text { being either solid or fluid. }
$$

Momentum equation for fluid phase:

$$
\begin{aligned}
\nabla \cdot\left(\alpha_{f} \rho_{f}\right. & \left.\vec{v}_{f} \vec{v}_{f}\right)=-\alpha_{f} \nabla P+\nabla \cdot \overline{\overline{v_{f}}}+\alpha_{f} \rho_{f} \vec{g}+K_{s f}\left(\overrightarrow{v_{s}}-\overrightarrow{v_{f}}\right) \\
& +C_{v m} \alpha_{f} \rho_{f}\left(\overrightarrow{v_{s}} \cdot \nabla \overrightarrow{v_{s}}-\overrightarrow{v_{f}} \cdot \nabla \overrightarrow{v_{f}}\right) \\
& +C_{L} \alpha_{s} \rho_{f}\left(\overrightarrow{v_{f}}-\overrightarrow{v_{s}}\right) \times\left(\nabla \times \overrightarrow{v_{f}}\right)
\end{aligned}
$$


Momentum equation for solid phase:

$$
\begin{aligned}
& \nabla .\left(\alpha_{s} \rho_{s} \vec{v}_{s} \vec{v}_{s}\right)=-\alpha_{s} \nabla P-\nabla P_{s}+\nabla \cdot \overline{\overline{v_{s}}}+\alpha_{s} \rho_{f} \vec{g} \\
& \quad+K_{s f}\left(\overrightarrow{v_{f}}-\overrightarrow{v_{s}}\right)+C_{v m} \alpha_{s} \rho_{f}\left(\overrightarrow{v_{f}} \cdot \nabla \overrightarrow{v_{f}}-\overrightarrow{v_{s}} \cdot \nabla \overrightarrow{v_{s}}\right) \\
& \quad+C_{L} \alpha_{s} \rho_{f}\left(\vec{v}_{s}-\vec{v}_{f}\right) \times\left(\nabla \times \overrightarrow{v_{f}}\right)
\end{aligned}
$$

\section{Turbulence Model}

The turbulent model is solved using RNG K- $\varepsilon$ model along with other additional conditions causing interfacial turbulent momentum transfer. The fluid phase Reynolds stress tensor is given by:

$$
\overline{\overline{\tau_{t, f}}}=-\frac{2}{3}\left(\rho_{f} k_{f}+\mu_{t, f} \nabla \vec{v}_{f}\right) \overline{\bar{I}}+\mu_{t, f}\left(\nabla \vec{v}_{f}+\nabla \vec{v}_{f}^{t r}\right)
$$

Here $\mu_{t, f}$ is the viscosity corresponding to turbulence. An analytical differential interrelationship for turbulent viscosity is provided with RNG K-E model for modelling the flow at lower Reynolds number. At large Reynolds number (which is the case in current study) this analytical correlation converts to:

$$
\mu_{t, f}=\rho_{f} C_{\mu} \frac{k_{f}^{2}}{\varepsilon_{f}} \text { With } C_{\mu}=0.09
$$

The prediction of turbulent kinetic energy $k_{f}$ and turbulent energy dissipation rate $\varepsilon_{f}$ by Standard Kepsilon and RNG K-epsilon approach is almost very much alike. Standard and RNG $k$-epsilon approach differ in such a fashion that RNG k-epsilon approach contains a supplementary expression in the epsilon equation:

$$
R_{\varepsilon}=\frac{C_{\mu} \rho \eta^{3}\left(1-\eta / \eta_{0}\right) \varepsilon^{2}}{\left(1+\beta \eta^{3}\right) k}
$$

Where, $\eta=S k / \varepsilon, \eta_{0}=4.38, \beta=0.012$, the constant parameters are taken as $\mathrm{C}_{\mu m}=0.0845, \mathrm{C}_{1 \varepsilon}=1.42, \mathrm{C}_{2 \varepsilon}=$ $1.68, C_{3 \varepsilon=1.3} \sigma_{k}=0.75, \sigma_{\varepsilon}=1.2$

\section{Wall Function}

Wall functions are defined as the collection of empirical and semi- empirical formulae used for obtaining accurate and better results at the wall boundary of the computational domain. Therefore the near wall boundary region of the flow domain demands exclusive treatment at the time of simulation due to the presence of higher gradient terms in this study. This is accomplished by selecting standard wall function available in RNG K-epsilon approach.

\section{NUMERICAL SOLUTIONS \\ Geometry and Mesh}

A pipe having $103 \mathrm{~mm}$ diameter and $5.5 \mathrm{~m}$ length has been modelled in ANSYS workbench design modular. Non uniform structured mesh has been generated in workbench using multi-zone method with hexa core elements. 7 inflation layers of smooth transition with a ratio of 0.272 are introduced for refining the mesh near the wall boundary of the flow domain. The mesh contains approximately 213594 elements. (Figure 1).

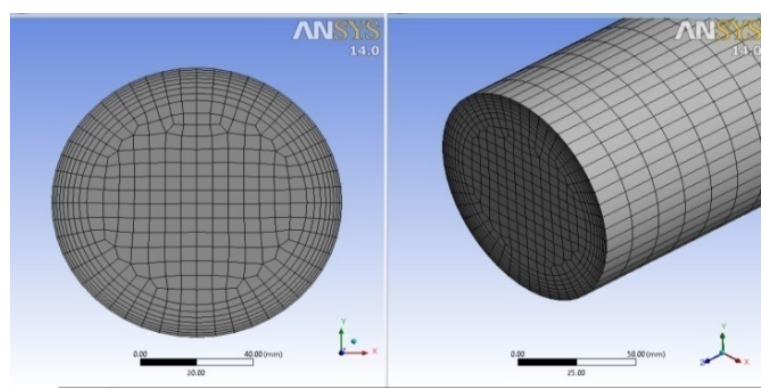

Figure 1. 2D and 3D view of meshed geometry used in this study 


\section{Boundary Conditions}

Boundary conditions need to be assigned to initiate the flow in the flow domain. Three different boundary conditions namely outlet boundary, wall boundary and inlet boundary are specified to the flow domain. At inlet boundary volume fraction i.e. $\alpha_{\mathrm{f}}=1-\alpha_{\mathrm{s}} ; \alpha_{\mathrm{s}}=\mathrm{C}_{\mathrm{vf}}\left(\alpha_{\mathrm{f}}\right.$ and $\alpha_{\mathrm{s}}$ are volume fraction of fluid and solid phase respectively, $C_{v f}$ is the solid volume fraction) and mixture velocity i.e. $V_{m}=v_{s}=v_{f}\left(V_{m}, v_{f}\right.$ and $v_{s}$ are mixture velocity, velocity of fluid phase and velocity of solid phase respectively) for both fluid and solid phase has been introduced. At wall boundary no slip boundary conditions are selected for liquid phase and full slip boundary conditions are selected on solid phase. A completely developed flow at the pipe outlet is used in current study for prediction of velocity distributions and concentration distributions.

\section{Grid Independency Test}

In numerical simulations there is a high recommendation of selecting an optimal mesh for the analysis of flow parameters for the sake of minimal error and better accuracy. For this reason a grid independency test is conducted to select the optimal mesh for final calculation. In this test seven different mesh containing 143 thousand, 171 thousand, 213 thousand, 287 thousand, 357 thousand, 393 thousand and 512 thousand elements have been selected. The flow problem is simulated for each mesh applying same boundary conditions in each case $\left(C_{v f}=0.4\right.$ and velocity $\left.V=5.4 \mathrm{~m} / \mathrm{s}\right)$ and the particle velocity distribution along the vertical centreline of the pipe outlet in y-direction is obtained (Figure 2).

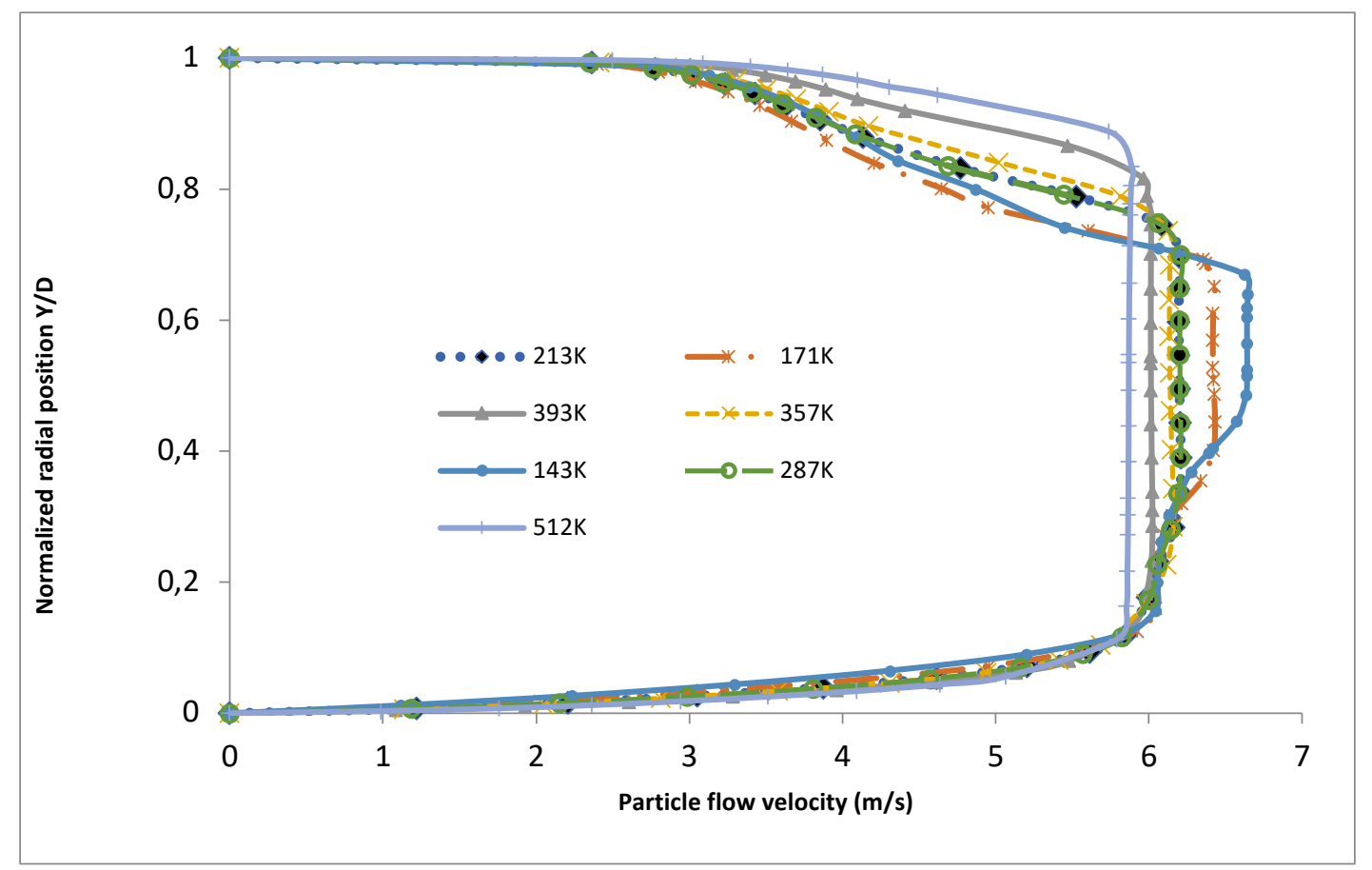

Figure 2. Plots of particle flow velocity distributions for different mesh

From Figure 2 it can be noticed that velocity distribution for the mesh containing 213 thousand elements is super imposing with the velocity distribution for the mesh containing 287 thousand elements, hence the mesh containing 213 thousand elements is selected as optimal mesh and is adopted for further simulation.

\section{Solution Method and Convergence Criteria}

In this current study the Navier- Stokes governing equations along with their closure parameters are solved using ANSYS FLUENT 14.0. Momentum and mass equations are solved by control volume finite difference approach. Turbulent kinetic energy, momentum equation and turbulent dissipation rate are discretized using second order upwind scheme while for discretizing the volume fraction first order upwind scheme is used in this study. For pressure and velocity coupling phase coupled SIMPLE algorithm is selected. Convergence of problem depends on the scaled residual. For this flow problem the residuals contains continuity, X-velocity, Y-velocity, Z-velocity for both the phases; $\mathrm{k}$ and $\varepsilon$ for phase 1 and volume fraction for phase 2 which need to be converged at some specific region. Application of these schemes confirmed better stability, accuracy and convergence of the flow problem. Moreover decreasing the value of under relaxation factors ensured better convergence of the problem. URF (under relaxation factor) for volume fraction has been reduced to 0.3 from 0.5 and for momentum it has been reduced from 0.7 to 0.5 . 


\section{RESULTS AND DISCUSSION}

This section shows the impact of solid particle size $\left(D_{p}\right)$ as well as solid volume fraction $\left(C_{v f}\right)$ on local concentration distribution of solid particles $\left[C\left(Y^{\prime}\right)\right]$, flow velocity $\left(\mathrm{V}_{\mathrm{m}}\right)$ and pressure drop $(\Delta \mathrm{P} / \mathrm{L})$ along the vertical centerline at pipe outlet cross section $\left(Y^{\prime}=\mathrm{Y} / \mathrm{D}\right.$ - in $\mathrm{Y}$ - direction). Solid volumetric concentration is determined taking the mean value of particle concentration along the vertical centreline, represented as:

$$
C_{\mathrm{vf}}=\frac{1}{2 \mathrm{y}} \int_{-\mathrm{y}}^{+\mathrm{y}} \alpha_{\mathrm{s}}\left(\mathrm{y}, \mathrm{Y}^{\prime}\right) \mathrm{dy}
$$

$\mathrm{WhereY}^{\prime}=\mathrm{Y} / \mathrm{D}, \mathrm{Y}$ is the height of the vertical centreline from top to bottom of the cross section of pipe at outlet in Y-direction.

\section{Effects of particle size and solid volume fraction on concentration distribution}

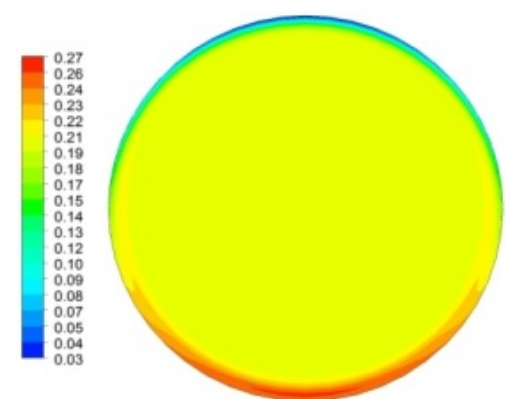

(a) $\mathrm{D}_{\mathrm{p}}=90 \mu \mathrm{m}$

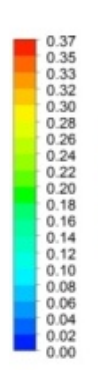

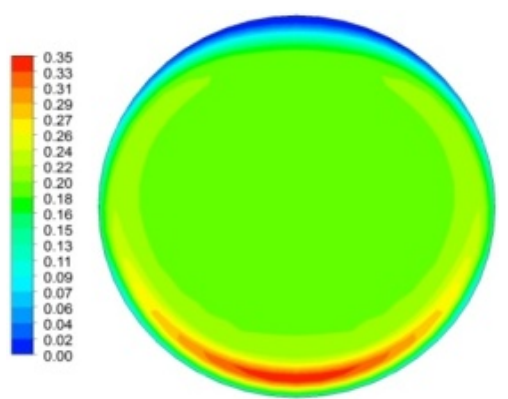

(b) $\mathrm{D}_{\mathrm{p}}=125 \mu \mathrm{m}$

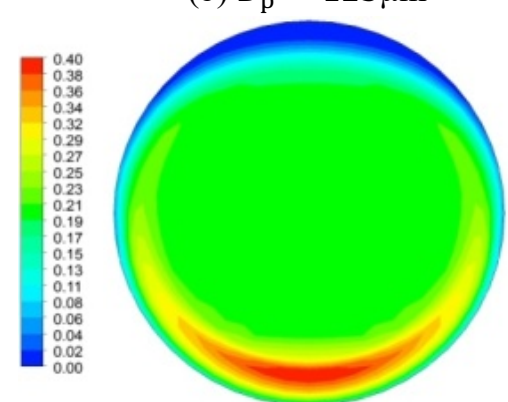

(d) $D_{p}=200 \mu m$

(c) $D_{p}=150 \mu \mathrm{m}$

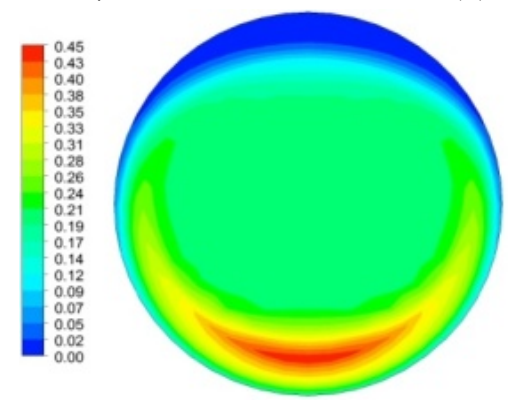

(e) $D_{p}=270 \mu \mathrm{m}$

Figure 3. Contours of particle concentration distribution for various particle sizes $\left[(a) D_{p}=90 \mu \mathrm{m}\right.$, (b) $D_{p}=$ $125 \mu \mathrm{m}$, (c) $\mathrm{D}_{\mathrm{p}}=150 \mu \mathrm{m}$, (d) $\mathrm{D}_{\mathrm{p}}=200 \mu \mathrm{m}$ and (e) $\left.\mathrm{D}_{\mathrm{p}}=270 \mu \mathrm{m}\right]$ at solid volumetric concentration $\mathrm{C}_{v f}=0.2$

From Figure 3(a)-(e) a significant change in solid particles local concentration distribution can be observed as the particle size becomes larger. It is noteworthy that the smallest particles $\left(D_{p}=90 \mu \mathrm{m}\right)$ are more buoyant and the particle distribution is homogenous in the fluid phase. The particle concentration zone is symmetrically distributed over the cross section of pipe at outlet. When the particles become larger in size from $D_{p}=90 \mu \mathrm{m}$ to $D_{p}=270 \mu \mathrm{m}$, the concentration zone is shifted towards the bottom portion of the pipe cross section because of gravitational effect; as a result the concentration distribution becomes asymmetrical. Because of this the larger particles concentrate at the pipe bottom constituting a stationary bed and refuse to travel further along with the fluid to the exit of the pipe. Maximum predicted particle concentrations accumulated at the pipe bottom are $0.27,0.36,0.37,0.40$ and 0.45 for particle size $D_{p}=90 \mu \mathrm{m}, 125 \mu \mathrm{m}, 150 \mu \mathrm{m}, 200 \mu \mathrm{m}$ and $270 \mu \mathrm{m}$ respectively. As the particle become larger in size the thickness of the bed also increases. These results show that in conveyance of sand-water slurry through pipeline, the larger particles accumulates at the bottom of the pipe thereby reducing effective flow area and which leads to poor productivity. 


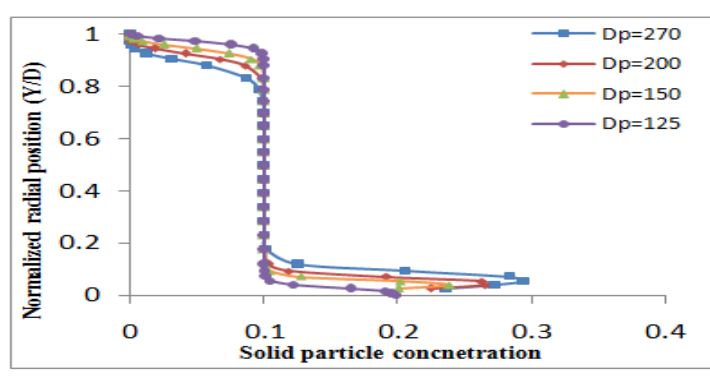

(a) $C_{v f}=0.1$

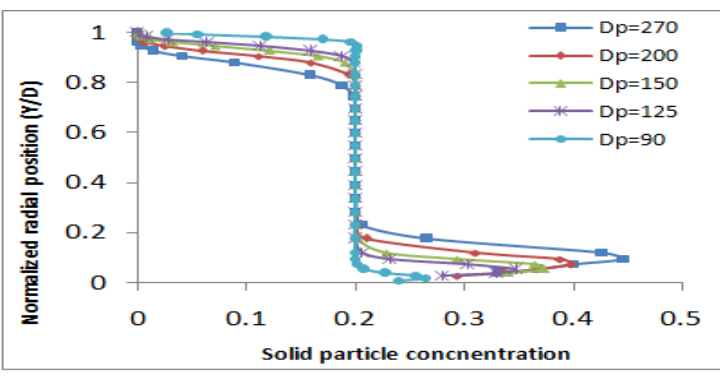

(b) $C_{v f}=0.2$

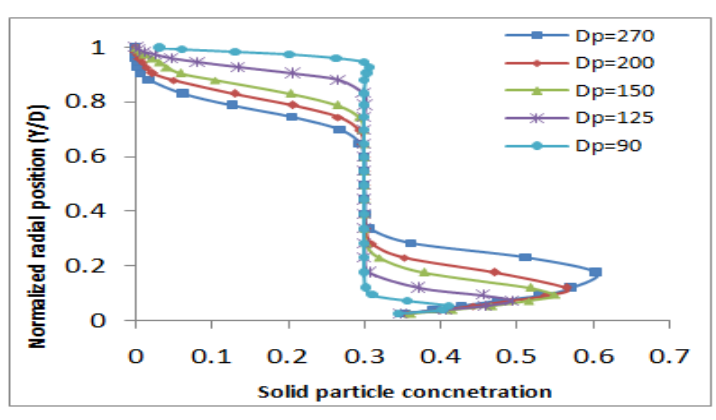

(c) $\mathrm{C}_{v f}=0.3$

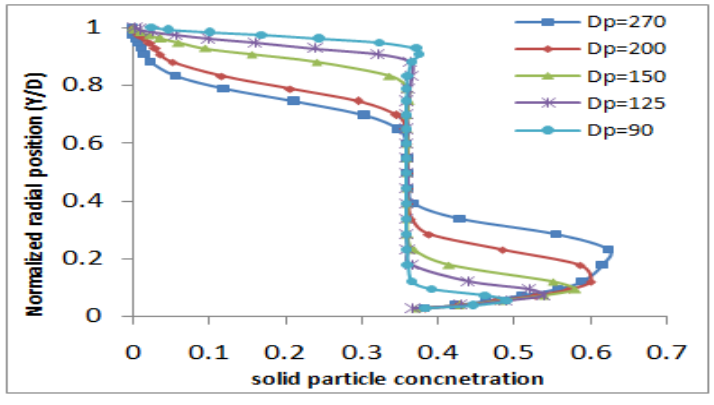

(d) $C_{v f}=0.36$

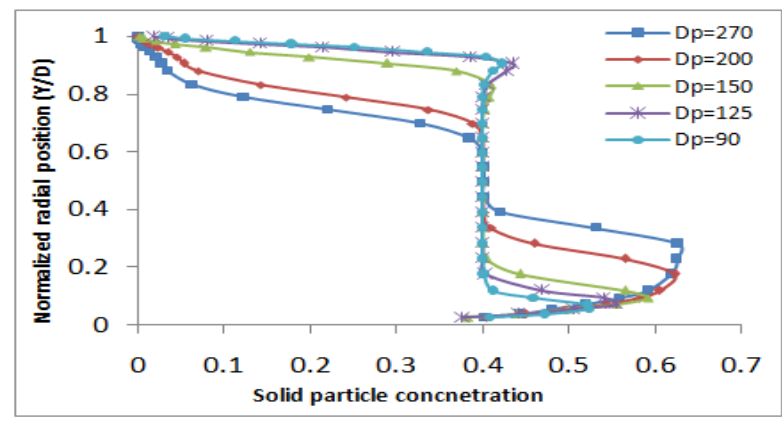

(e) $C_{v f}=0.4$

Figure 4. Plots of influence of solid particle size ( $D_{p}=90 \mu \mathrm{m}, 125 \mu \mathrm{m}, 150 \mu \mathrm{m}, 200 \mu \mathrm{m}$ and $\left.270 \mu \mathrm{m}\right)$ on local concentration distribution at different solid volumetric concentration $\left[(a) C_{v f}=0.1\right.$, (b) $C_{v f}=0.2$, (c) $C_{v f}=0.3$, (d) $C_{\mathrm{vf}}=0.36$ and (e) $\left.C_{\mathrm{vf}}=0.4\right]$

Figure 4(a)-(e) show the variation of local concentration distribution of the solid particles at five different solid volumetric concentration level viz. $C_{v f}=0.1, C_{v f}=0.2, C_{v f}=0.3, C_{v f}=0.36$ and $C_{v f}=0.4$ with varying solid particle size. These plots show the effect of fluid turbulence on the suspension of solid particles which changes from suspended to sluggish at the pipe bottom as the particle size increases for each constant solid volumetric concentration level. Furthermore it can be noticed that suspension of solid particles in fluid increases with the increase in solid volumetric concentration level for each particle size. At $C_{v f}=0.1$ [FIG 4(a)] most of the solid particles are accumulated at the pipe bottom, while at $C_{v f}=0.4$ the solid particles are seen to be suspended from the pipe bottom. This is the effect of increase in turbulent energy at higher solid volumetric concentration which causes the particle suspension. In addition to this no remarkable change in concentration distributions can be observed for smallest particle size $\left(D_{p}=90 \mu \mathrm{m}\right)$ at different solid volumetric concentration level because the particles are fine and flow velocity is greater than the deposition velocity. But for particle size $D_{p}=270 \mu \mathrm{m}$, the concentration distributions disintegrate due to the weak interactions among the particles. As the solid volumetric concentration increases from $C_{v f}=0.1$ to 0.4 a strong particle-particle bond becomes vivid thereby increasing the suspension of the solid particles in the fluid. [Figure 5 (a)-(c)]. 


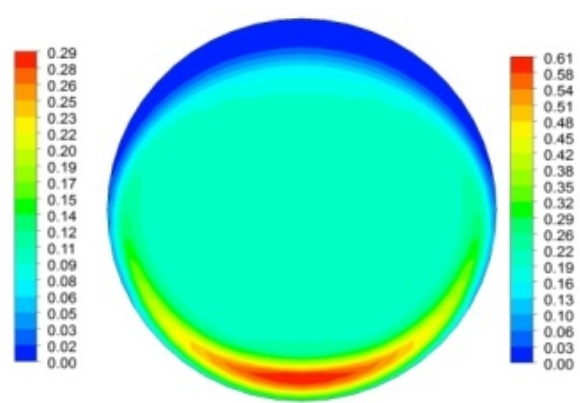

(a) $\mathrm{C}_{v f}=0.1$

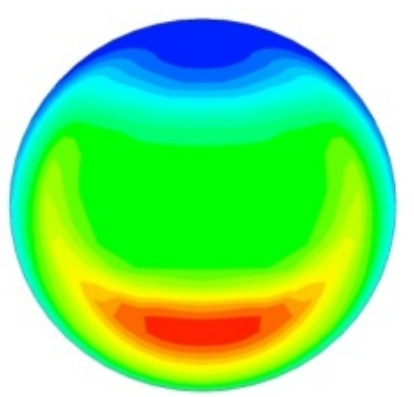

(b) $\mathrm{C}_{v f}=0.3$

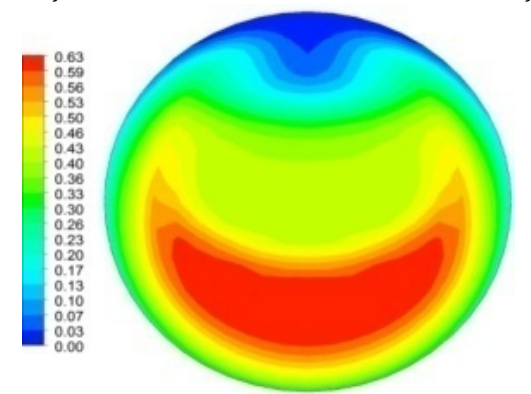

(c) $\mathrm{C}_{v f}=0.4$

Figure 5. Contours of solid particle concentration distributions at different solid volumetric concentration level $\left[(\mathrm{a}) \mathrm{C}_{\mathrm{vf}}=0.1\right.$, (b) $\mathrm{C}_{\mathrm{vf}}=0.3$, (c) $\left.\mathrm{C}_{\mathrm{vf}}=0.4\right]$ for a constant particle size $\mathrm{D}_{\mathrm{p}}=270 \mu \mathrm{m}$.

\section{Impact of particle size and solid volumetric concentration on flow velocity}

From Figure 6(a)-(c) it can be observed that the distribution of particle velocity is asymmetrical about the central axis. However the degree of asymmetry is affected by particle size. At a given solid volumetric concentration level the velocity distribution becomes more distorted as the particles become larger in size from $D_{p}=90 \mu \mathrm{m}$ to $270 \mu \mathrm{m}$. [Figure 6(c)]. This may be the result of accumulation of coarse particles at the pipe bottom due to gravitational effect. Moreover the degree of distortion of particle velocity is influenced by solid volumetric concentration. At low solid volumetric concentration i.e. $C_{v f}=0.2$ the distortion of velocity distribution is less [Figure 6(a)] and it increases with the increase in solid volumetric concentration i.e. $C_{v f}=0.4$ [Figure 6(c)]. This might be the effect of increased turbulence energy at higher solid volumetric concentration. In addition to this it is noteworthy that the particle velocity becomes less with the decrease in particle size for each solid volumetric concentration level, this is due to the fact that smaller particles show more buoyancy effect which leads to symmetrical distribution and blending of the particles with the fluid which causes smoother flow of the particles through the pipeline.

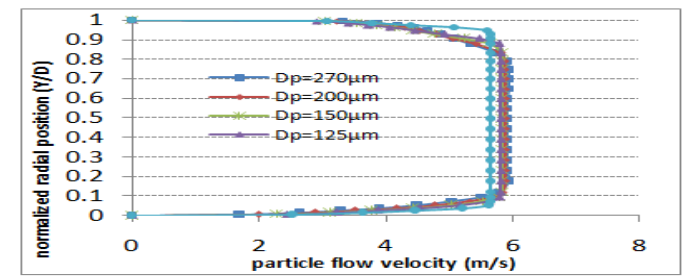

(a) $C_{v f}=0.2$

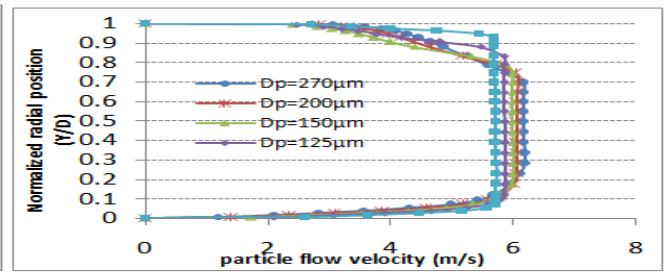

(b) $C_{v f}=0.3$

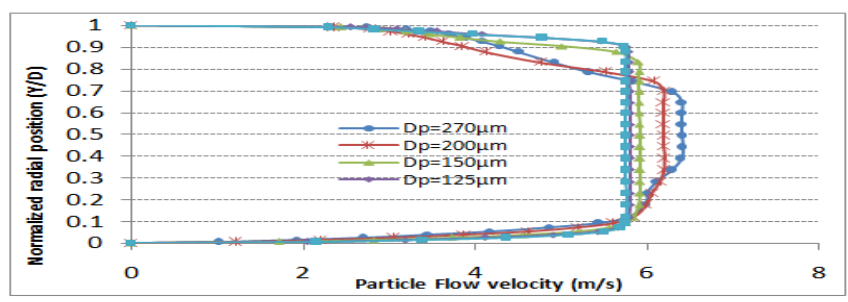

(c) $C_{v f}=0.4$

Figure 6. Plots of solid particle velocity distributions for different particle sizes at solid volumetric concentration level of (a) $C_{v f}=0.2$, (b) $C_{v f}=0.3$ and (c) $C_{v f}=0.4$ 


\section{Effect of particle size on pressure drop}

Figure 7 shows the effect of the size of solid particles on pressure drop at various solid volumetric concentration level viz. $C_{v f}=0.1, C_{v f}=0.3$ and $_{v f}=0.4$.

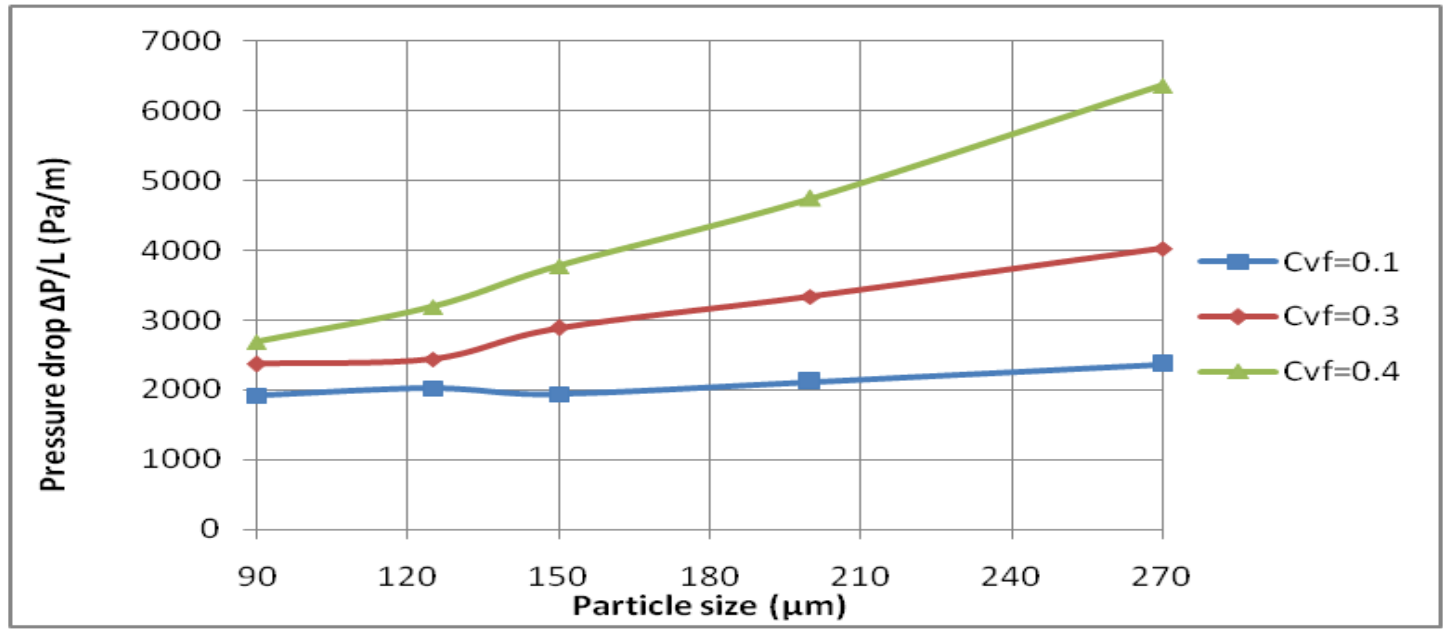

Figure 7. Plots of the effect of the size of solid particles $\left(D_{p}\right)$ on pressure drop at different solid volumetric concentrations.

From Figure 7 it can be noticed that the pressure drop rises as particles become larger in size. The coarser particles $\left(D_{p}>90 \mu \mathrm{m}\right)$ tend to accumulate at the pipe bottom thereby blocking a part of effective flow area. This raises the turbulence and flow velocity in the effective flow area which leads to increase in Reynolds number. A correlation of Reynolds number with pressure drop can be found in many literature which shows that pressure drop is directly proportional to turbulence of the flow, hence with the rise in Reynolds number (turbulence) the pressure drop increases. On the contrary the smaller particles are well suspended in the fluid because of turbulence effect, which increases effective viscosity of suspension therefore decrease in Reynolds number. Hence the pressure drop is less for smaller particle size. $\left(D_{p}=90 \mu \mathrm{m}\right)$. Moreover it can be noticed that the degree of increase in pressure drop becomes more rapid and abrupt at higher solid volumetric concentrations $\left(C_{v f}=0.4\right)$.

\section{Effect of solid volume fraction on pressure drop}

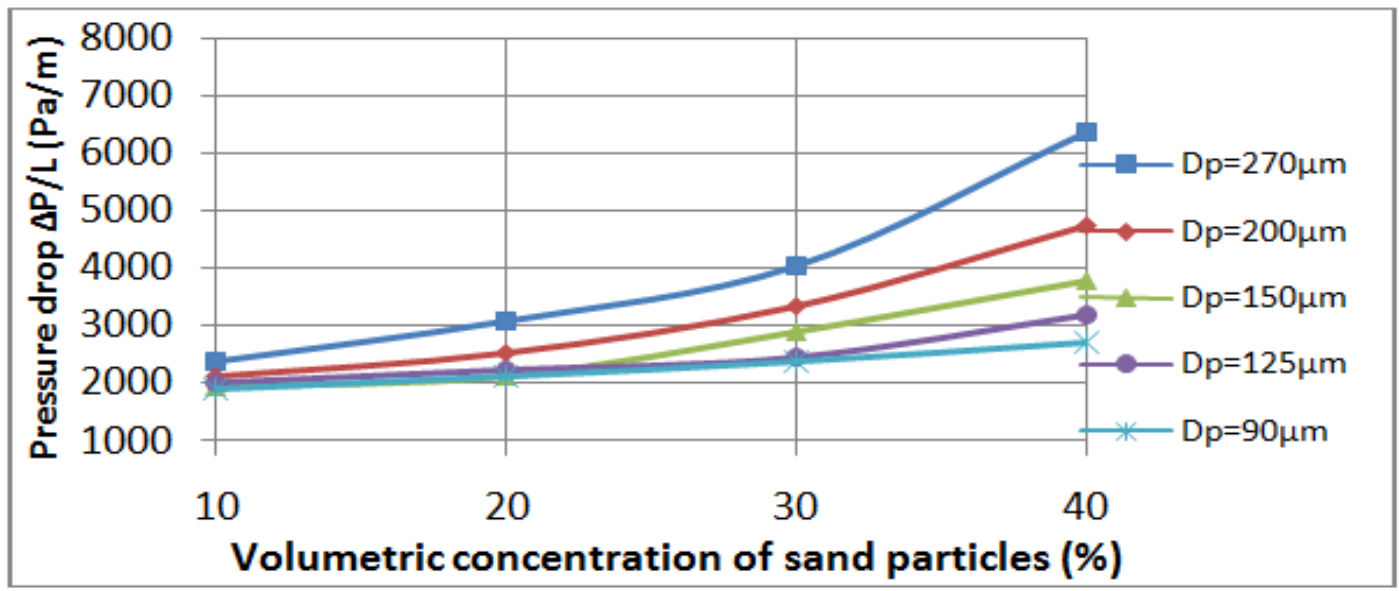

Figure 8. Effect of solid volumetric concentration $\left(C_{v f}\right)$ on pressure drop at different particle size.

From Figure 8 it might be noticed that pressure drop increases with the rise in solid volumetric concentrations for each constant particle size. As the solid volumetric concentration increases, the interaction among the solid particles, solid-fluid interaction and solid-wall interaction also increases, which is responsible for the increase in turbulence (Reynolds number). As a result, the pressure drop also increases at higher solid volumetric concentrations. It can also be observed that the rate of increase in pressure drop becomes more rapid at larger particle size $\left(D_{p}=270 \mu \mathrm{m}\right)$. 


\section{Mathematical model for pressure drop in terms of particle size and volume fraction of solid particles}

The impact of size of the solid particles on pressure drop at different solid volumetric concentration is discussed in section 4.3. A mathematical relationship is developed for analytical calculation of the influence of the size of solid particles on pressure drop at different solid volumetric concentration. Initially an exponential graph was plotted for pressure drop with solid particle size to predict the functional relationship between them. Then all the data of variation of pressure drop at different solid volumetric concentration level were plotted against particle size. (Fig7). The mathematical model is represented as:

$$
\frac{\Delta P}{L}=A\left(B e^{n D_{p}}\right)
$$

Here $\frac{\Delta P}{L}$ is the pressure drop along the pipe length, $D_{p}$ is the size of solid particles; A, B and C are constants $A=1705$

$\mathrm{B}=\left\{\begin{array}{l}1.00 \text { for } \mathrm{C}_{v f}=0.1 \\ 1.03 \text { for } \mathrm{C}_{v f}=0.3 \\ 1.04 \text { for } \mathrm{C}_{v f}=0.4\end{array}\right.$

$\mathrm{n}=\left\{\begin{array}{l}0.001 \text { for } C_{v f}=0.1 \\ 0.003 \text { for } C_{v f}=0.3 \\ 0.004 \text { for } C_{v f}=0.4\end{array}\right.$

The effect of solid volumetric concentration on pressure drop is discussed in section 4.4. A generalized mathematical relationship is developed for the analytical estimation of the influence of solid volumetric concentration on pressure drop. Initially an exponential graph was plotted for pressure drop with solid volumetric concentration to predict the functional relationship between them. Then all the data of variation of pressure drop for different particle size were plotted against solid volumetric concentration (Fig 8). The developed mathematical model is represented as:

$$
\frac{\Delta P}{L}=P\left(Q e^{\alpha C_{v f}}\right)
$$

Here $\frac{\Delta P}{L}$ is the pressure drop along the pipe length, $\mathrm{C}_{v f}$ is the solid volumetric concentration; $\mathrm{P}, \mathrm{Q}$ and $\mathrm{R}$ are constants.

$P=1705$

$\mathrm{Q}=\left\{\begin{array}{l}1.00 \text { for } D_{p}=90 \mu \mathrm{m} \\ 1.27 \text { for } D_{p}=125 \mu \mathrm{m} \\ 2.09 \text { for } D_{p}=150 \mu \mathrm{m} \\ 2.45 \text { for } D_{p}=200 \mu \mathrm{m} \\ 2.9 \text { for } D_{p}=270 \mu \mathrm{m}\end{array}\right.$

$\alpha=\left\{\begin{array}{l}0.011 \text { for } D_{p}=90 \mu \mathrm{m} \\ 0.014 \text { for } D_{p}=125 \mu \mathrm{m} \\ 0.023 \text { for } D_{p}=150 \mu \mathrm{m} \\ 0.027 \text { for } D_{p}=200 \mu \mathrm{m} \\ 0.032 \text { for } D_{p}=270 \mu \mathrm{m}\end{array}\right.$

\section{Validation of the study}

The intention of this study is to legitimize the simulated predicted outcome of the effect of flow velocity on pressure drop at different solid volumetric concentrations of the settling slurries in horizontal pipe. The verification is achieved by correlating simulated outcome with the experimental outcome of pressure drop available in the work of Gillies et. al [15]. Figure show the impact of particle flow velocity on pressure drop at different solid volumetric concentration. Differential pressure along the length $(\Delta \mathrm{P} / \mathrm{L})$ is taken on $\mathrm{Y}$-axis and particle flow 
velocity has been taken on X-axis for plotting the graphs. For comparing the simulated and experimental results, Plot digitizer software is used to extract the coordinates from the experimental results.

Figure 9 (a)-(e) show the analogous relation between simulated and experimental pressure drop contours for a flow velocity of $5.4 \mathrm{~m} / \mathrm{s}$ and particle size of $270 \mu \mathrm{m}$ at different solid volumetric concentration level viz. 0.1 , $0.2,0.3,0.36$ and 0.4 respectively. Different trend in development of pressure drop with an increase in velocity can be observed and generally increase in velocity brings around the rise in pressure drop. The rate of rise in pressure drop is less at low velocity and rises abruptly at higher velocity.

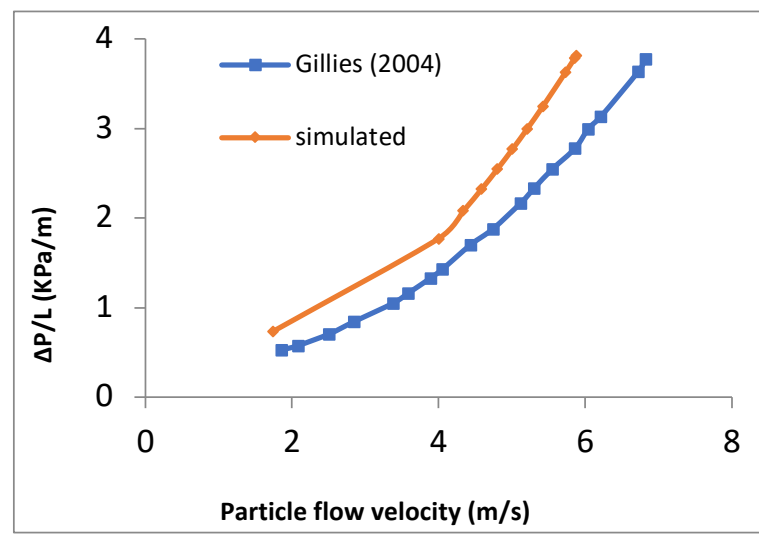

(a) $C_{v f}=0.1$

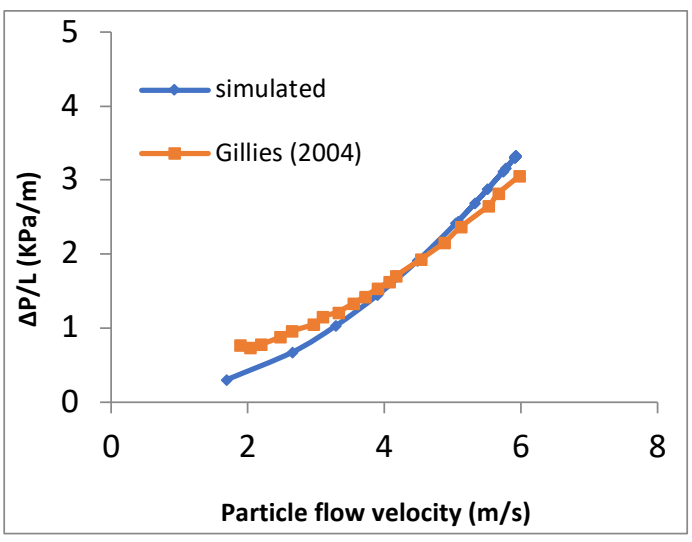

(b) $\mathrm{C}_{v f}=0.2$

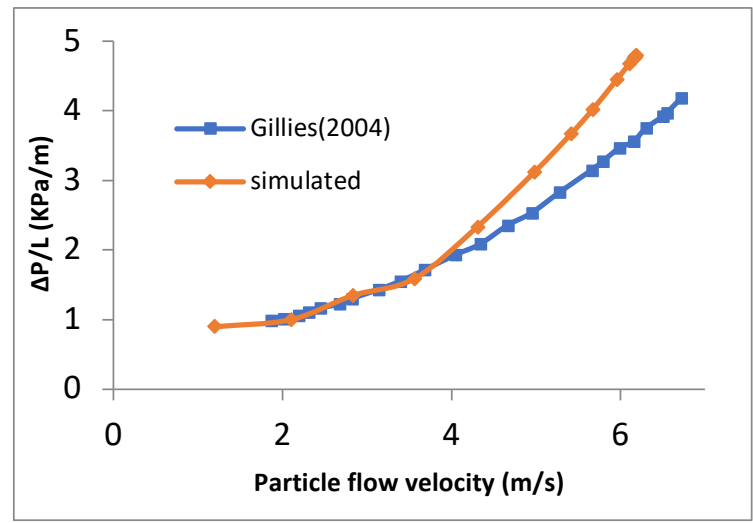

(c) $\mathrm{C}_{v f}=0.3$

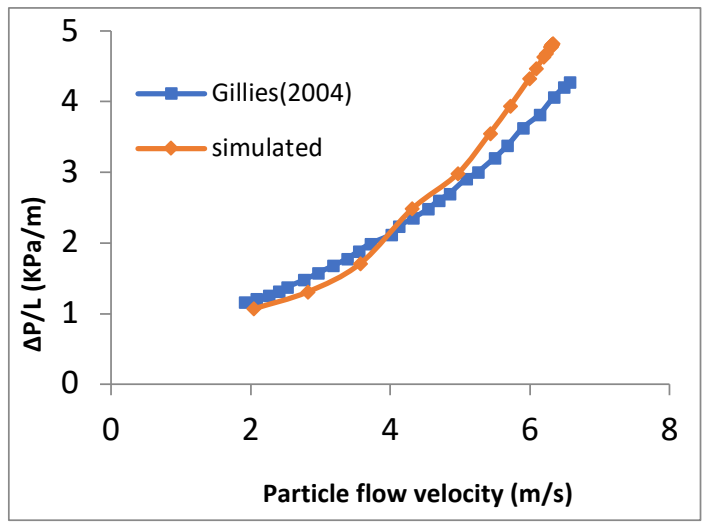

(d) $C_{v f}=0.36$

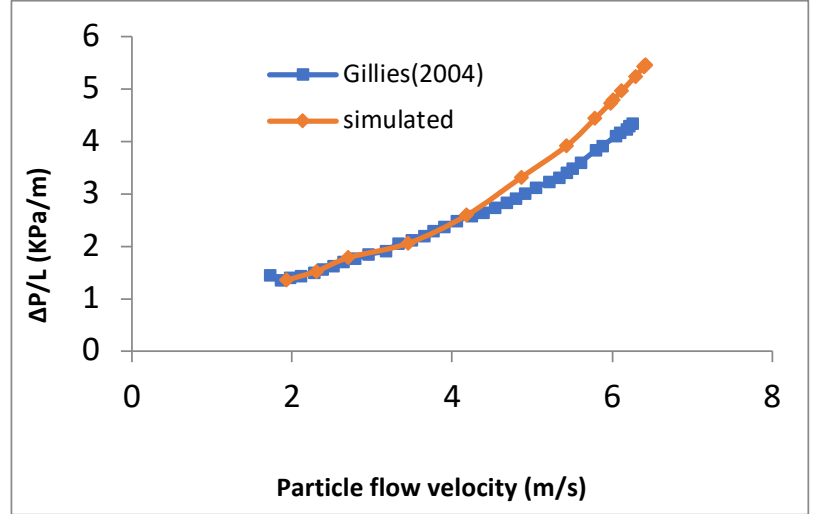

(e) $\mathrm{C}_{v f}=0.4$

Figure 9. (a)-(e) Comparison of simulated and experimental effect of particle flow velocity on pressure drop at different solid volumetric concentrations.

\section{CONCLUSIONS}

The study presents a 3D numerical investigation of two phase flow of sand-water slurry using CFD technique. Five different particle sizes viz. $90 \mu \mathrm{m}, 125 \mu \mathrm{m}, 150 \mu \mathrm{m}, 200 \mu \mathrm{m}$ and $270 \mu \mathrm{m}$ and particle density of 2650 $\mathrm{kg} / \mathrm{m}^{3}$ is undertaken. Granular version of Eulerian two-phase model and RNG K- $\varepsilon$ turbulence model are selected for the mono-dispersed sand particles. The following conclusions can be drawn based on the current study:

- As the particle size increases from $90 \mu \mathrm{m}$ to $270 \mu \mathrm{m}$, the concentration zone is shifted towards the bottom half of the pipeline and thereby; larger particles accumulate at pipe bottom due to gravitational effect. It 
makes the concentration distribution asymmetrical that can lead to creation of bed at the pipe bottom thereby reducing the effective flow area and reducing productivity.

- For each constant particle size, as the solid volumetric concentration increases from $20 \%$ to $40 \%$, the velocity distribution becomes more asymmetrical and distorted because of the rise in turbulence.

- The rise in pressure drop is higher for particle size of $(>90 \mu \mathrm{m})$. This is because the coarse particles form a bed at the pipe bottom thereby, blocking a part of effective flow area which raises the particle flow velocity and hence increases turbulence. On the other hand, the rise in pressure drop decreases as the particle size of $90 \mu \mathrm{m}$.

- For each constant particle size, the pressure drop rises with the increase in solid volumetric concentration level, because at high concentration the turbulence of the flow increases.

- Moreover, a generalized mathematical relationship has been developed for better understanding of the functional relations amongst particle size, solid volumetric concentrations and pressure drop. These relationships will be very helpful in the setup of an experimental model for sand/water slurry flow pipelines. Furthermore, the experimental setup made with such optimum outcomes will be cost effective and physically viable. Hence, the present study is highly useful and applicable in view of experimental research method in this field.

\section{NOMENCLATURE}

\begin{tabular}{|c|c|c|c|}
\hline $\mathrm{C}_{\mathrm{vf}}$ & Efflux concentration (by volume) & $\mathrm{C}_{\mathrm{D}}$ & Drag coefficient \\
\hline $\mathrm{D}$ & Diameter of pipe (mm) & $\Delta \mathrm{P}_{\mathrm{s}}$ & Solid pressure gradient \\
\hline $\mathrm{D}_{\mathrm{p}}$ & Particle diameter $(\mu \mathrm{m})$ & $\nabla \mathrm{P}$ & Static pressure gradient $(\mathrm{Pa})$ \\
\hline $\mathrm{L}$ & Length of the pipe (m) & $\mathrm{K}_{\mathrm{sf}}$ & Inter-phasial momentum exchange coefficient \\
\hline g & Acceleration due to gravity $\left(\mathrm{m} / \mathrm{s}^{2}\right)$ & $C\left(y^{\prime}\right)$ & Local concentration distribution of solid particles \\
\hline $\overrightarrow{v_{s}}$ & Velocity of solid phase $(\mathrm{m} / \mathrm{s})$ & $\operatorname{Re}$ & Reynolds number \\
\hline $\overrightarrow{v_{f}}$ & Velocity of fluid phase $(\mathrm{m} / \mathrm{s})$ & A & constant \\
\hline $\mathrm{C}_{\mathrm{vm}}$ & Coefficient of virtual mass & $\mathrm{B}$ & constant \\
\hline $\mathrm{C}_{\mathrm{L}}$ & Lift force & $\mathrm{n}$ & constant \\
\hline$\overline{\overline{\tau_{t, f}}}$ & Reynolds stress tensor & $\mathrm{P}$ & constant \\
\hline$\overline{\overline{\tau_{s}}}$ & Viscous stress tensor for solid phase & Q & constant \\
\hline $\mathrm{V}$ & Mean flow velocity $(\mathrm{m} / \mathrm{s})$ & & \\
\hline \multicolumn{4}{|c|}{ Greek symbols } \\
\hline$\overline{\bar{I}}$ & Identity tensor & $\alpha_{\mathrm{s}, \max }$ & Static settled concentration, \\
\hline$\frac{\lambda_{\mathrm{s}}}{\overline{\tau_{f}}}$ & $\begin{array}{l}\text { Bulk viscosity of solid phase } \\
\text { stress tensor for fluid phase }\end{array}$ & $\begin{array}{l}\alpha_{\mathrm{s}} \\
\alpha_{\mathrm{f}}\end{array}$ & $\begin{array}{l}\text { Solid phase concentration } \\
\text { Liquid phase concentration }\end{array}$ \\
\hline$\alpha$ & constant & $\rho$ & Mass density of solid $\mathrm{kg} / \mathrm{m}^{3}$ \\
\hline \multicolumn{4}{|c|}{ Abbreviations } \\
\hline CFD & Computational Fluid Dynamics & ANSYS & Analysis System \\
\hline
\end{tabular}

\section{REFERENCES}

[1] O'Brien, M.P. Review of the theory of turbulent flow and its relations to sediment transport, Transaction of the American Geophysical Union 1933;14, 487-491.

[2] Rouse, H. Modern conceptions of the mechanics of fluid turbulence, Transactions of ASCE, 1937; 102, 463-505.

[3] Shook, C. A., Daniel, S. M. Flow of suspensions of solids in pipelines: Part I, Flow with a stable stationary deposit, The Canadian Journal of Chemical Engineering, 1965; 43(2), 56-61.

[4] Wasp, E. J., Aude, T. C.: Deposition velocities, transition velocities, and spatial distribution of solids in slurry pipelines, In Presented at the 1st International British Hydromechanics Research Association Hydraulic Transport of Solids in Pipes Conference, War Wickshire Univ, Conventry, England,1970, Sept. 1-4. (No. H4 Proceeding). 
[5] Turian, R. M., Yuan, T. F. Flow of slurries in pipelines. AIChE Journal, 1977; 23(3), 232-243.

[6] Seshadri, V., Malhotra, R.C., Sundar, K.S. Concentration and size distribution of solids in a slurry pipeline, in: Proc. 11th Nat. Conference on Fluid mechanics and fluid power, B.H.E.L., Hyderabad; 1982.

[7] Roco, M. C., Shook, C. A. Modeling of slurry flow: the effect of particle size. The Canadian Journal of Chemical Engineering, 1983; 61(4), 494-503.

[8] Roco, M. C., Shook, C. A. Computational method for coal slurry pipelines with heterogeneous size distribution, Powder Technology, 1984; 39(2), 159-176.

[9] Doron, P., Granica, D., Barnea, D. Slurry flow in horizontal pipes-experimental and modelling, International Journal of Multiphase Flow, 1987; 13(4), 535-547.

[10] Gillies, R.G., Shook, C.A., Wilson, K.C. An improved two layer model for horizontal slurry pipeline flow, The Canadian Journal of Chemical Engineering, 1991; 69, 173-178.

[11] Gillies, R. G., Shook, C. A., Xu, J. Modelling heterogeneous slurry flows at high velocities, The Canadian Journal of Chemical Engineering, 2004; 82(5), 1060-1065.

[12] Gillies, R. G., Hill, K. B., Mckibben, M. J., Shook, C. A. Solids transport by laminar Newtonianflows. Powder Technology, 104(3), 1999; 269-277.

[13] Gillies, R. G., Shook, C. A. Modelling high concentration settling slurry flows, The Canadian journal of chemical Engineering, 78(4), 2000; 709-716.

[14] Kaushal, D. R., Seshadri, V., Singh, S. N. Prediction of concentration and particle size distribution in the flow of multi-sized particulate slurry through rectangular duct, Applied Mathematical Modeling, 2002; 26(10), 941-952.

[15] Gillies, R. G., Shook, C. A., Xu, J. Modelling heterogeneous slurry flows at high velocities, The Canadian Journal of Chemical Engineering, 2004; 82(5), 1060-1065.

[16] Kaushal, D. R., Sato, K., Toyota, T., Funatsu, K., Tomita, Y.Effect of particle size distribution on pressure drop and concentration profile in pipeline flow of highly concentrated slurry, International Journal of Multiphase Flow, 2005; 31(7), 809-823.

[17] Monteiro, A. C., Bansal, P. K. Pressure drop characteristics and rheological modeling of ice slurry flow in pipes, International journal of refrigeration, 2010; 33(8), 1523-1532.

[18] Lahiri, S.K., Ghanta, K.C. Slurry flow modelling by CFD, Chemical Industry \& Chemical Engineering Quarterly, 2010; 16 (4) 295-308.

[19] Kaushal, D. R., Thinglas, T., Tomita, Y., Kuchii, S., Tsukamoto, H. CFD modeling for pipeline flow of fine particles at high concentration, International Journal of Multiphase Flow, 2012; 43, 85-100.

[20] Messa, G. V., Malavasi, S. Improvements in the numerical prediction of fully-suspended slurry flow in horizontal pipes, Powder Technology, 2015; 270, 358-367.

[21] Nabil, T., El-Sawaf, I., El-Nahhas, K. Sand-water slurry flow modelling in a horizontal pipeline by computational fluid dynamics technique, International Water Technology Journal, 2014; 4(1), 13.

[22] Swamy, M., Díez, N. G., Twerda, A. Numerical modelling of the slurry flow in pipelines and prediction of flow regimes, Computational Methods in Multiphase Flow, 2015; 8(89), 311.

[23] Gopaliya, M. K., Kaushal, D. R. Modeling of sand-water slurry flow through horizontal pipe using CFD, Journal of Hydrology and Hydromechanics, 2016; 64(3), 261-272.

[24] Kumar, N., Gopaliya, M. K., Kaushal, D. R. Experimental investigations and CFD modeling for flow of highly concentrated iron ore slurry through horizontal pipeline. Particulate Science and Technology, 2018; $1-19$.

[25] Wang, J., Wang, S., Zhang, T. and Battaglia, F. Matheatical and experimental investigation on pressure drop of heterogeneous ice slurry flow in horizontal pipes, International Journal of Heat and Mass Transfer, 2017; 108, 2381-2392.

[26] Onokoko, L., Poirier, M., Galanis, N., Poncet, S. Experimental and numerical investigation of isothermal ice slurry flow, International Journal of Thermal Sciences, 2018; 126, 82-95. 